\title{
Analysis of the chemical components of hydatid fluid from Echinococcus granulosus
}

\author{
Juyi $L i^{[1],[2], ~ Y a n ~ J u}{ }^{[1],[3]}$, Xiufang Wang ${ }^{[4]}$, Zhaoqing Zhang ${ }^{[4]}$, Junliang $L i^{[1],[3]}$, \\ Mingxing Zhu ${ }^{[1],[3]}$ and Wei Zhao ${ }^{[3],[5]}$
}

[1]. School of Basic Medical Sciences, Ningxia Medical University, Yinchuan, Ningxia Hui Autonomous Region, China. [2]. Department of Pharmacy, The Third Hospital of Wuhan, Wuhan, Hubei Province, China. [3]. Cystic Hydatid Disease Laboratory, Ningxia Medical University, Yinchuan, Ningxia Hui Autonomous Region, China. [4]. Department of Rehabilitation, The Third Hospital of Wuhan, Wuhan, Hubei Province, China. [5]. Center of Scientific Technology, Ningxia Medical University, Yinchuan, Ningxia Hui Autonomous Region, China.

\begin{abstract}
Introduction: The aim of this study was to explore the environment of Echinococcus granulosus (E. granulosus) protoscolices and their relationship with their host. Methods: Proteins from the hydatid-cyst fluid (HCF) from E. granulosus were identified by proteomics. An inductively coupled plasma atomic emission spectrometer (ICP-AES) was used to determine the elements, an automatic biochemical analyzer was used to detect the types and levels of biochemical indices, and an automatic amino acid analyzer was used to detect the types and levels of amino acids in the E. granulosus HCF. Results: I) Approximately 30 protein spots and 21 peptide mass fingerprints (PMF) were acquired in the two-dimensional gel electrophoresis (2-DE) pattern of hydatid fluid; II) We detected 10 chemical elements in the cyst fluid, including sodium, potassium, calcium, magnesium, copper, and zinc; III) We measured 19 biochemical metabolites in the cyst fluid, and the amount of most of these metabolites was lower than that in normal human serum; IV) We detected 17 free amino acids and measured some of these, including alanine, glycine, and valine. Conclusions: We identified and measured many chemical components of the cyst fluid, providing a theoretical basis for developing new drugs to prevent and treat hydatid disease by inhibiting or blocking nutrition, metabolism, and other functions of the pathogen.
\end{abstract}

Keywords: Echinococcus granulosus. Hydatid fluid. Two-dimensional gel electrophoresis.

Peptide mass fingerprints. MASCOT software.

\section{INTRODUCTION}

Echinococcosis, also called hydatid disease, is a zoonos is caused by the larval stage of Echinococcus. Echinococcosis affects humans and other mammals, such as sheep, dogs, rodents, and horses ${ }^{1}$. Once Echinococcus infects a host, the oncosphere of Echinococcus will develop into a cyst. The cyst forms a relatively stable internal environment to avoiddamage to the larvae from the host immune system. Hydatid cyst fluid (HCF) is an important component of the internal environment and fills the entire cyst. HCF is a clear or clear yellow liquid with antigenic properties. $\mathrm{HCF}$ provides needed nutrition forlarval growth, playing an important role in their lifecycle of Echinococcus.

Only a few comprehensive studies of the chemical composition of HCF in human liver have been reported. Previous studies focused on livestock such as sheep and cattle. Capron and Yarzabal discovered antigen 5 and antigen B in HCF through sodium dodecyl sulfate-polyacrylamide gel

Address to: Dr. Wei Zhao. Center of Scientific Technology/Ningxia Medical University. 750004 Yinchuan, Ningxia Hui Autonomous Region, China.

Phone: 8627 6889-4893

e-mail: lisan727@163.com

Received 6 August 2013

Accepted 3 October 2013 electrophoresis (SDS-PAGE) and western blot analysis ${ }^{2,3}$. Zhu used improved two-dimensional polyacrylamide electrophoresis to identify 111 proteins in the liver HCF of infected sheep ${ }^{4}$. Chemale attempted to analyze proteins in liver HCF of cattle but failed to establish a 2-DE database because of the effect of highly abundant albumin and immunoglobulin ${ }^{5}$. Forty-eight E. granulosus proteins were identified by $\mathrm{Aziz}^{6}$; however, many previously identified components of HCF were not included. HCF proteins are composed of $44 \%$ albumin, $39 \% \alpha$-globulin and $\beta$-globulin, and $17 \% \gamma$-globulin ${ }^{7}$. Li determined that liver HCF and lung HCF from sheep and yak contained 17 amino acids, but the total protein level was very low, equivalent to a level of approximately $1-2 \%$ in serum ${ }^{8}$. Similarly, the cholesterol level was also found to be low (approximately 12\% in serum). Polysaccharides, together with proteins and lipids, were present in sheep liver $\mathrm{HCF}^{9}$. Other researchers also detected urea, uric acid, proteins and amino acids, lipids, electrolytes, glucose, glycogen, many trace elements, and proteases, for example, in the $\mathrm{HCF}^{10-13}$. In summary, these studies established a baseline assessment of the chemical constituents of HCF.

In the past few years, little progress has been made in establishing the chemical constitution of HCF. In this chapter, we report the results of a comprehensive analysis of the environment of the larvae. Because HCF exchanges substances with the host for the survival and reproduction of protoscolexes, an understanding of the larval environment will aid in identifying 
the essential components of parasite growth and, potentially, in developing novel methods for preventing E. granulosus infection.

\section{METHODS}

\section{Purification of hydatid-cyst fluid}

Human HCF was collected after the surgical removal of fertile cysts from patients with cystic hydatid disease in The General Hospital of Ningxia Medical University. In total, 21 cysts of different sizes were isolated in a germ-free environment, and $55 \mathrm{ml}$ of cyst fluid was aspirated from these cysts using sterile needles under aseptic conditions and centrifuged at $10,000 \mathrm{~g}$ for $15 \mathrm{~min}$ at $4^{\circ} \mathrm{C}$ to remove particles. The supernatant fluid was stored at $-80^{\circ} \mathrm{C}$ until use.

\section{Electrophoresis and in-gel digestion}

First, $20 \mathrm{ml}$ of cyst liquid was pre-frozen at $-85^{\circ} \mathrm{C}$ for $5 \mathrm{~h}$ and then placed in the freeze-dryer $\left(-60^{\circ} \mathrm{C}\right.$, vacuum $)$ overnight. After $24 \mathrm{~h}$, the cyst liquid was freeze-dried into a powder. The powder was lysed using lysis buffer [ $9 \mathrm{~mol} / 1$ urea, $4 \%$ 3-(3-cholamidopropyl) dimethyl-ammonio-1-propane sulfonate (CHAPS), $1 \%$ dithiothreitol (DTT), and $0.5 \%$ protease-inhibitor cocktail], fully oscillated and blended at $4^{\circ} \mathrm{C}$ for $1 \mathrm{~h}$, and centrifuged at $12,000 \mathrm{~g}$ at $4^{\circ} \mathrm{C}$ for $30 \mathrm{~min}$. The final supernatant fluid was stored at $-85^{\circ} \mathrm{C}$ until use. To remove salt, lipids, and undesired detergents, cleanup was performed with the ReadyPrepTM 2-D Cleanup Kit (BIO-RAD) California (USA). Next, the AurumTM Serum Protein Mini Kit (BIO-RAD) was used to remove the most abundant proteins. The protein pellets were re-solubilized in immobilized $\mathrm{pH}$ gradient (IPG) rehydration buffer (7M urea, $2 \mathrm{M}$ thiourea, $2 \%$ CHAPS, $50 \mathrm{mM}$ DTT, $0.2 \%$ Bio-Lyte ampholyte, $0.001 \%$ bromophenol blue) and then centrifuged. The supernatant was held at $4{ }^{\circ} \mathrm{C}$. The total protein concentration for each sample was determined using the Bradford assay ${ }^{14}$. Areas of the $17 \mathrm{~cm}$ IPG strips (BIO-RAD) were wetted with the above sample in a rehydration tray, and mineral oil was added to prevent evaporation. The isoelectric focusing (IEF) program was set as follows: step 1:250V (linear) for 30min; step 2: 500V (rapid) for $1 \mathrm{~h}$; step 3: 4,000V (linear) for $4 \mathrm{~h}$; step 4: 4,000V (rapid) for 30,000Vh; and step 5: 500V (rapid) for $20 \mathrm{~h}$ (holding step). A total of $2 \mathrm{ml}$ of equilibration buffer I [6mol/1 urea, 0.375mol/1 Tris-HCL (pH 8.8), 20\% glycerol, $2 \%$ SDS, $2 \%$ DTT] was added to the top of the strip in an 11-cm equilibration tray, followed by gentle rocking for $15 \mathrm{~min}$. Equilibration buffer I was discarded and replaced with equilibration buffer II [6mol/1 urea, $0.375 \mathrm{~mol} / 1$ Tris-HCL $(\mathrm{pH}$ 8.8 ), $20 \%$ glycerol, $2 \%$ SDS, $2.5 \%$ iodoacetamide], followed by gentle rocking for $15 \mathrm{~min}$. IPG was loaded onto an SDSPAGE gel composed of a $12 \%$ separation gel, and the proteins were stained using Coomassie Brilliant Blue. Each protein spot was sliced and destained 3 to 4 times by incubation in $50 \%$ acetonitrile and $25 \mathrm{mM} \mathrm{NH}_{4} \mathrm{HCO}_{3}$ for $10 \mathrm{~min}$. After destaining, the gel pieces were placed in $10 \mathrm{mM}$ DTT/100 $\mathrm{mM}$ ammonium bicarbonate solution and deoxidated for $1 \mathrm{~h}$ at $65^{\circ} \mathrm{C}$. The DTT solution was removed after cooling to room temperature. Then, the samples were alkylated with $55 \mathrm{mM}$ iodoacetamide $/ 100 \mathrm{mM}$ ammonium bicarbonate solution for $45 \mathrm{~min}$ at room temperature in the dark and then dried in a vacuum centrifuge. The dried gel pieces were subsequently rehydrated with $20 \mu 1$ of $100 \mathrm{mM}$ $\mathrm{NH}_{4} \mathrm{HCO}_{3}$ containing $12.5 \mathrm{ng} / \mu \mathrm{l}$ trypsin (Sigma) for $16 \mathrm{~h}$ at $37^{\circ} \mathrm{C}$ and then ultrasonically treated in $15 \mu 1$ of $0.1 \%$ trifluoroacetic acid (TFA). The extracts were analyzed by matrix-assisted laser desorption/ionizationtime-of-flight mass spectrometry (MALDI-TOF-MS).

\section{Analysis of inorganic elements and biochemical parameters in hydatid-cyst fluid}

Cyst fluid was added to an equal volume of acid digestion mixture (nitric acid and perchloric acid at a ratio of 4:1). Samples were heated in an automatic electric digestive device. After cooling, a clear solution formed and was diluted to $10 \mathrm{ml}$ with $1 \%$ nitric acid. An equal volume of acid digestion mixture treated the same way served as the control. The blank control, the standard for each element, the elements in the controls, and the elements in the samples were sequentially determined.

The automatic biochemical analyzer (AU-400, Olympus) was calibrated and controlled with quality-control liquid and standard liquid (Olympus) and then used to analyze cyst fluid. The results are shown as the mean \pm standard deviation.

\section{Free amino acid analysis of hydatid-cyst fluid}

Cyst fluid was mixed with an equal volume of $10 \%$ sulfosalicylic acid and centrifuged at $10,000 \mathrm{~g}$ for $15 \mathrm{~min}$. The supernatant was passed through a $0.45-\mu \mathrm{m}$ filter, and amino acids were detected by the auto amino-acid analyzer (HITACHI $\mathrm{L}-8900$ ). The fluid was separated using $4.6 \mathrm{~mm} \times 60 \mathrm{~mm}$ sulfonic acid cation resin in the lithium citrate buffer ( $\mathrm{PH} 2.8-4.1)$ at $0.3 \mathrm{ml} / \mathrm{min}$ for $30 \mathrm{~min}$. The reaction temperature was $135^{\circ} \mathrm{C}$. The flow rate of the color development reagent ninhydrin was $0.25 \mathrm{ml} / \mathrm{min}$. The results are shown as the average amino acid concentrations \pm standard deviation.

\section{RESULTS}

\section{Composition of parasite proteins in hydatid-cyst fluid}

We identified 30 protein spots using PD Quest 8.0 2D analysis software (Figure 1). The molecular weight of most of these proteins ranged from 43 to $97 \mathrm{kDa}$. The isoelectric points of the 21 proteins identified in the cyst fluid ranged from 5 to 9 . The data were uploaded to the swiss pro program and searched by Mascot (Table 1). Protein scores greater than 75 were considered significant $(\mathrm{p}<0.05)$. We found three proteins, namely $\beta$-hemoglobin $\left(\mathrm{N}^{\mathrm{o}} 3\right)$, albumin ( $\left.\mathrm{N}^{\circ} 12\right)$, and serum transferrin $\left(\mathrm{N}^{\circ} 18\right)$, in the cyst fluid.

\section{Inorganic element content and biochemical properties of hydatid-cyst fluid}

The mineral elements in the hydatid fluid are shown in Table 2, and the biochemical indices of the HCF of E. granulosus are shown in Table 3. Several biochemical metabolites and proteins were measured in the cyst fluid. The amounts of many biochemical components, such as glucose, $\alpha$-hydroxybutyric 
TABLE 1 - Proteins identified by peptide mass fingerprints. Peptide mass fingerprints from the protein spots cut from the gel (Figure 1) used in the MASCOT search.

\begin{tabular}{|c|c|c|c|c|c|c|}
\hline Spot number & Mass & Isoelectric point & Score & Expected & Matches & Protein name and species \\
\hline 1 & 15,763 & 7.52 & 27 & $1.1 \mathrm{e}+03$ & 5 & GRPE_BACFN \\
\hline 2 & 15,680 & 7.02 & 36 & $1.4 \mathrm{e}+02$ & 3 & RS5_CALS8 \\
\hline 4 & 25,238 & 5.57 & 28 & $7.9 \mathrm{e}+02$ & 6 & AHPD_ACIBL \\
\hline 5 & 42,350 & 6.12 & 34 & $2 \mathrm{e}+02$ & 9 & MINN_BACCN \\
\hline 7 & 58,837 & 4.66 & 49 & 7.1 & 10 & PYREL_METBU \\
\hline 8 & 57,985 & 6.87 & 63 & 0.25 & 21 & SYP_HELPH \\
\hline 9 & 58,953 & 9.41 & 53 & 2.4 & 20 & PURA_METMA \\
\hline 10 & 73,357 & 5.72 & 59 & 0.68 & 36 & ALBU_HUMAN \\
\hline 14 & 75,388 & 6.25 & 41 & 45 & 9 & LDHD_STAAC \\
\hline 15 & 75,462 & 6.26 & 32 & $3.2 \mathrm{e}+02$ & 3 & Y195_BPT7 \\
\hline 16 & 75,394 & 6.41 & 51 & 3.8 & 14 & Y262_STAES \\
\hline 17 & 75,410 & 6.41 & 51 & 3.8 & 14 & Y262_STAES \\
\hline 18 & 71,317 & 5.92 & 106 & $1.3 e-05$ & 36 & ALBU_HUMAN \\
\hline 19 & 98,230 & 6.05 & 25 & $1.5 \mathrm{e}+03$ & 4 & MT2_YARLI \\
\hline 20 & 98,782 & 5.95 & 35 & $1.5 \mathrm{e}+02$ & 9 & CB061_MOUSE \\
\hline 21 & 16,570 & 9.47 & 46 & 13 & 14 & DOT1_EMENI \\
\hline
\end{tabular}

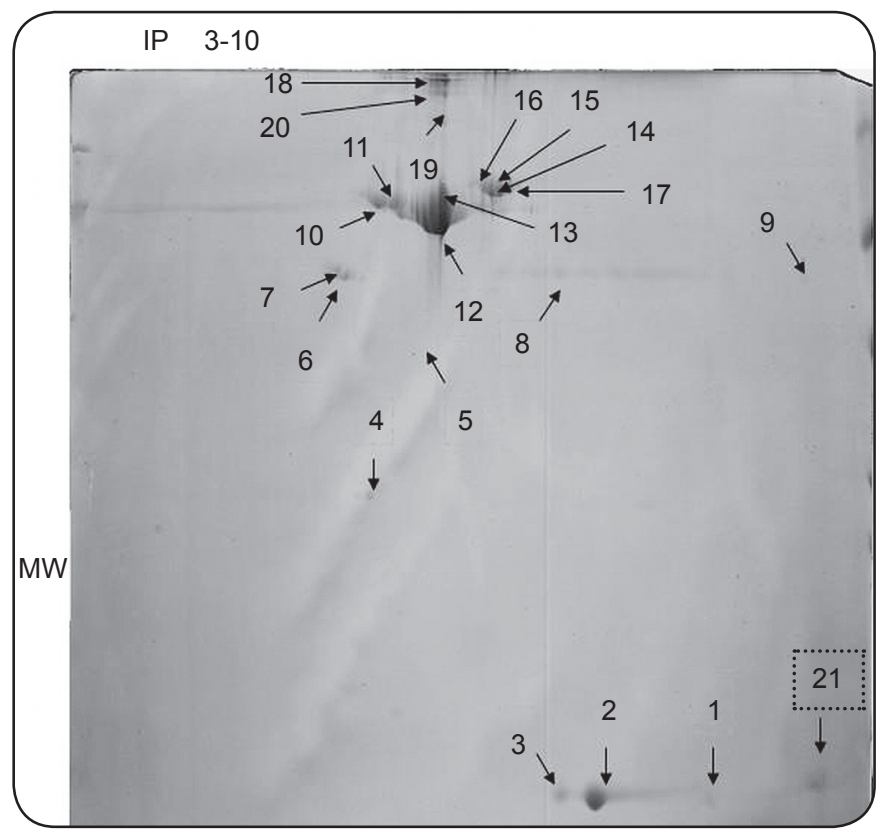

FIGURE 1 - 2-DE gel of HCF protein extracts that were first run on a $17 \mathrm{~cm}$ $\mathrm{pH} 3-10$ IPG strip in the first dimension and then run on a $20 \times 20-\mathrm{cm} 12 \%$ SDS-PAGE gel in the second dimension; $400 \mu \mathrm{g}$ of total proteins was loaded. 2-DE: two-dimensional gel electrophoresis; HCF: hydatid-cyst fluid; IPG: immobilized pH gradient; SDS-PAGE: sodium dodecyl sulfate-polyacrylamide gel electrophoresis; IP: isoelectric point; MW: molecular weight.
TABLE 2 - The mineral element composition of hydatid fluid. The elements were determined using the inductively coupled plasma atomic emission spectrometer.

\begin{tabular}{lcc}
\hline Element & $\bar{\chi}_{ \pm \mathrm{S}}(\mathrm{mg} / \mathrm{l})$ & Analytical line $(\mathrm{nm})$ \\
\hline Calcium & $113.93 \pm 34.05$ & 315.88 \\
Potassium & $216.76 \pm 2.85$ & 766.49 \\
Magnesium & $44.21 \pm 4.05$ & 285.21 \\
Ferrum & - & 238.20 \\
Copper & $0.01 \pm 0.01$ & 324.75 \\
Chromium & - & 267.71 \\
Cadmium & - & 214.44 \\
Zinc & $0.12 \pm 0.05$ & 213.86 \\
Selenium & - & 196.03 \\
Sodium & $1554.46 \pm 61.09$ & 589.59 \\
\hline
\end{tabular}

acid, triglycerides, uric acid, and creatine kinase, are lower than those in normal human serum, with each component typically constituting a serum equivalent of approximately $1 \%$ of the HCF. The cholesterol level is also lower in cyst fluid; however, 
TABLE 3 - Biochemical indices of the hydatid-cyst fluid of Echinococcus granulosus. Biochemical indexes of hydatid-cyst fluid detected by the automatic biochemical analyzer (AU-400, Olympus).

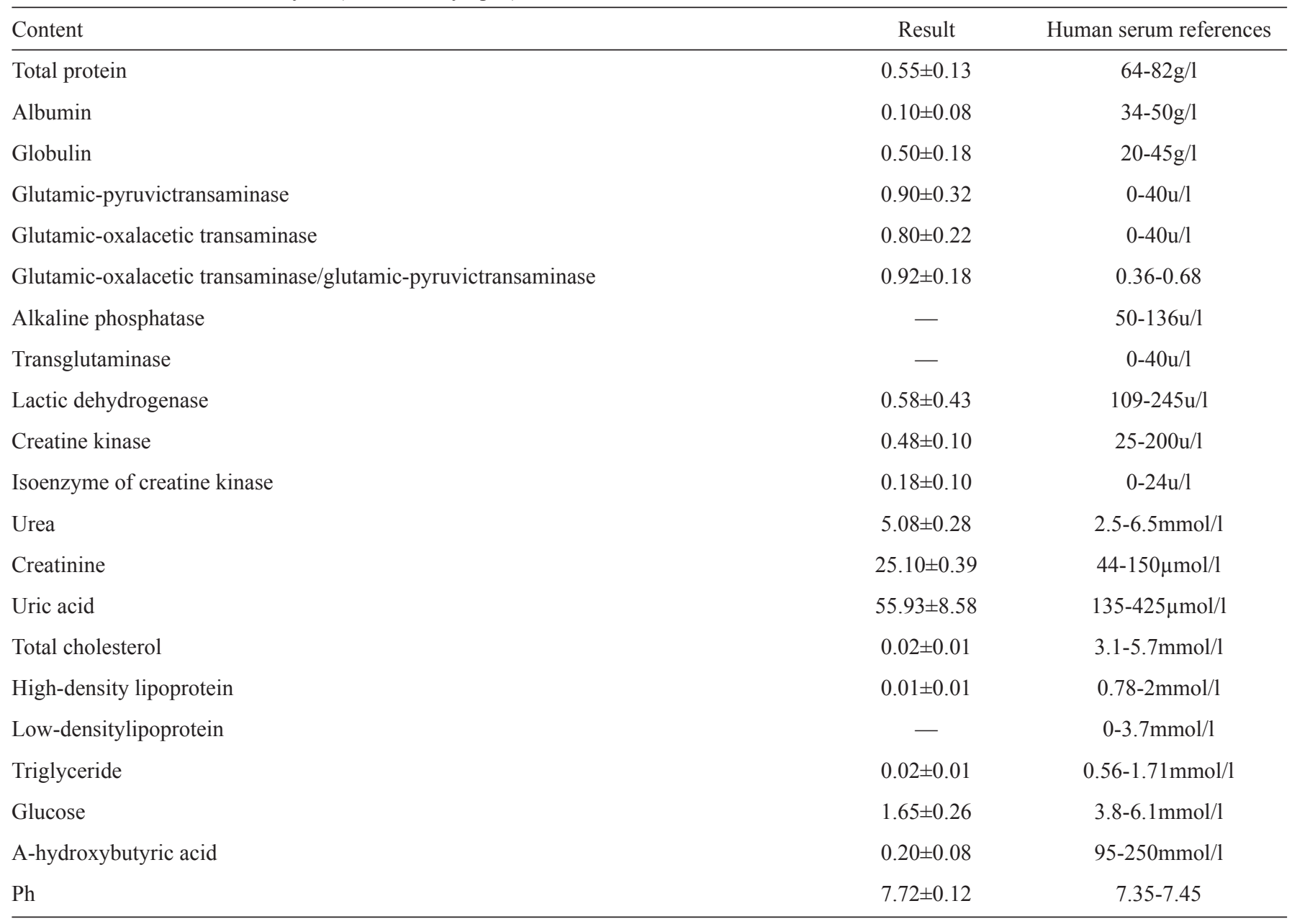

the ratio of glutamic-oxalacetic transaminase to glutamicpyruvictransaminase is higher than that in normal human serum, and the levels of both enzymes are relatively high. The levels of urea, low-density lipoprotein, glutamic-pyruvic transaminase, the isoenzyme of creatine kinase, transglutaminase, and glutamic-oxalacetic transaminase are similar in cyst fluid and in normal human serum.

\section{Analysis of amino acids in hydatid-cyst fluid}

The results of the amino acid analysis in the HCF of E. granulosus are shown in Table 4. We measured the levels of 17 amino acids in the cyst fluid. The level of alanine was highest, followed by glycine. We failed to detect aspartic acid, most likely due to its low concentration.

\section{DISCUSSION}

Three proteins, $\beta$-hemoglobin, albumin, and serum transferrin, were found in the cyst fluid. Transferrins are ironbinding blood-plasma glycoproteins that control the level of free iron in biological fluids and participate in the body's resistance to infection. Thus, the transferrin in cyst fluid is likely able to transport the iron required for the growth of E. granulosus. Albumin is the most abundant protein in plasma. Its main function in mammals is to maintain oncotic pressure. It is also a transport protein for, e.g., fatty acids, unconjugated bilirubin, and thyroid hormones. Albumin is also a nutrient for cells. Human albumin in the cyst fluid provides energy to the larvae. Hemoglobin is a composite protein containing iron, which is composed of ferroheme and globin and plays an important role in transporting oxygen and carbon dioxide. $\beta$-hemoglobin is a subtype of hemoglobin that is detected in cyst fluid. $\beta$-hemoglobin provides necessary energy to larvae by transporting oxygen and carbon dioxide.

The concentrations of inorganic elements in cyst fluid vary across hosts. The concentration of $\mathrm{Na}^{2+}$ in the cyst fluid was approximately half that in healthy human serum, while the levels of $\mathrm{K}^{+}, \mathrm{Mg}^{2+}$, and $\mathrm{Ca}^{2+}$ were higher in the cyst fluid (Table 2). One important role of $\mathrm{Ca}^{2+}$ is to control the $\mathrm{pH}$ and thus prevent acidity in the $\mathrm{HCF}$, and $\mathrm{Mg}^{2+}$ and $\mathrm{Ca}^{2+}$ are found in calcareous bodies in the cyst $\mathrm{t}^{15}$. These results established the concentrations of inorganic elements in cyst fluid and indicated that the entrance 
TABLE 4 - Analysis of amino acids in the hydatid-cyst fluid of Echinococcus granulosus. Analysis of amino acids in hydatid-cyst fluid detected by the auto-amino-acid analyzer (Hitachi L-8900).

\begin{tabular}{|c|c|}
\hline Amino acids & Content $(\mathrm{nmol} / \mu \mathrm{l})$ \\
\hline Glycine (GLY) & $4.49 \pm 0.59$ \\
\hline Leucine (LEU) & $0.99 \pm 0.29$ \\
\hline Methionine (MET) & $0.23 \pm 0.06$ \\
\hline Tyrosine (TYR) & $0.19 \pm 0.04$ \\
\hline Histidine (HIS) & $0.51 \pm 0.06$ \\
\hline Threonine (THR) & $0.39 \pm 0.04$ \\
\hline Alanine (ALA) & $13.33 \pm 2.83$ \\
\hline Isoleucine (ILE) & $0.63 \pm 0.15$ \\
\hline Cysteine (CYS) & $0.17 \pm 0.04$ \\
\hline Lysine (LYS) & $0.77 \pm 0.02$ \\
\hline Aspartate (ASP) & - \\
\hline Valine (VAL) & $3.21 \pm 0.98$ \\
\hline Phenylalanine (PHE) & $0.11 \pm 0.03$ \\
\hline Proline (PRO) & $0.86 \pm 0.28$ \\
\hline Serine (SER) & $0.34 \pm 0.06$ \\
\hline Glutamic (GLU) & $0.24 \pm 0.03$ \\
\hline Arginine (ARG) & $0.14 \pm 0.02$ \\
\hline Ammonia (residue) $\mathrm{NH}_{3}$ & $0.42 \pm 0.06$ \\
\hline
\end{tabular}

of these elements into the cyst is strictly controlled to meet the requirements of parasite growth.

We found that the levels of both glutamic-oxalacetic transaminase and glutamic-pyruvictransaminase are high in cyst fluid (Table 4), suggesting a high level of transamination in larvae. High activity of these enzymes may also be related to a liver disorder caused by liver echinococcosis. The level of uric acid in cyst fluid is also very high. Uric acid and ascorbic acid are strong reducing agents (electron donors) and potent antioxidants. In humans, over half the antioxidant capacity of blood plasma is derived from uric acid ${ }^{16}$, and plasma uric acid levels correlate with longevity in primates and other mammals ${ }^{17}$. Thus, uric acid may play a protective role during the growth of protoscolexes.

Alanine is enriched in cyst fluid compared with other amino acids. High levels of alanine were also reported in cyst fluid in other studies ${ }^{18}$. In our assays, aspartic acid was shown to be absent from cyst fluid. The intake of amino acids in hydatid disease could occur in two steps: amino acids first cross the cyst wall by free diffusion and then enter the cyst fluid through free diffusion and active transport mediated by specific receptors in the germinal layer ${ }^{19}$. The absence of aspartic acid suggests that the cyst membrane does not contain aspartic acid receptors and that the larvae cannot synthesize this amino acid. Therefore, the larvae must obtain aspartic acid through transamination, as is consistent with the high levels of transaminases found in the HCF. The levels of amino acids vary remarkably in cyst fluid from different hosts (pigs, sheep, cattle, and humans) (20,21. $^{2}$.

These results indicate that the entrance of all organic and inorganic chemicals depends on parasite requirements. The chemical composition of cyst fluid plays an important role in protecting against hydatid disease and providing nutritional material. Knowledge of parasite nutrition can aid in identifying new ways to prevent hydatid disease by changing the nutrient composition of cyst fluid or blocking nutrition and metabolic pathways.

\section{CONFLICT OF INTEREST}

The authors declare that there is no conflict of interest.

\section{FINANCIAL SUPPORT}

This work was supported by grants from the National Natural Science Foundation of China ( ${ }^{\circ}$ 30960360).

\section{REFERENCES}

1. Alvaro D, Cecilia C, Florencia I, Gerardo L, Jose OP, Fernando F. Understanding the laminated layer of larval Echinococcus. I: structure. Cell 2011; 27:204-213.

2. Capron A, Biguet J, Vernes A, Afchain D. Antigenic structure of helminthes. Immunological aspects of the host-parasite relationship. Pathol Biol 1968; 16:121-138

3. Yahzabal LA, Dupas H, Bout D, Naquira F, Capron A. Echinococcus granulosus: the distribution of hydatid fluid antigens in the tissues of the larval stage. II. Localization of the thermostable lipoprotein of parasitic origin (antigen B). Exp Parasitol 1977; 42:115-120.

4. Zhu CL, Ye BH, Zhu XL, Zhao XZ, Huang J, Zhang JY. 2-D electrophoresis preliminary research of hydatid cyst fluid, scolex and cyst wall. Chinese J Zoonoses 1989; 5:27-29.

5. Chemale G, van Rossum AJ, Jefferies JR, Barrett J, Brophy PM, Ferreira HB, et al. Proteomic analysis of the larval stage of the parasite Echinococcus granulosus: Causative agent of cystic hydatid disease. Proteomics 2003; 3:1633-1636.

6. Aziz A, Zhang W, Li J, Loukas A, McManus DP, Mulvenna J. Proteomic characterisation of Echinococcus granulosus hydatid cyst fluid from sheep, cattle and humans. Proteomics 2011; 21:1-13.

7. Zhao WX. Human Parasitology. People's Medical Publishing House; 1987; p. 514.

8. Li ZH, Zhu XQ, Sun J. Basic composition analysis of cyst fluid in livestocks. Chinese J Vet Sci Technol 1985; 11:36-37.

9. Kang JF, Fu YC, Feng XH. Preliminary analysis of hydatid cyst fluid and antigen. J Xing Jiang Med College 1986; 9:290-292.

10. Frayha GJ, Haddad R. Comparative chemical composition of protoscolices and hydatid cyst fluid of Echinococcus granulosus (Cestoda). Int J Parasitol 1980; 10:359-364.

11. Goodchild CG, Kagan IG. Comparison of proteins in hydatid fluid and serum by means of electrophoresis. J Parasitol 1961; 47:175-180.

12. Kagan IG, Norman L. Antigenic analysis of Echinococcus antigens by agar diffusion techniques. Am J Trop Med Hyg 1961a; 10:727-734. 
13. Kagan IG, Goodchild CG. Paper electrophoresis of sera from man and experimental animals infected with various helminths. J Parasitol 1961b; 47:373-377.

14. Assady M, Farahnak A, Golestani A, Esharghian M. Superoxide dismutase (SOD) enzyme activity assay in Fasciola spp. parasites and liver tissue extract. Iran J Parasitol 2011; 6:17-22.

15. Rayha GJ, Haddad R. Comparative chemical composition of protoscolices and hydatid cyst fluiColtortid of Echinococcus granulosus (Cestoda). Int J Parasitol 1980; 10:359-364.

16. Maxwell SRJ, Thomason H, Sandler D, Leguen C, Baxter MA, Thorpe GHG, et al. Antioxidant status in patients with uncomplicated insulindependent and non-insulin-dependent diabetes mellitus. European J Clin Investigation 1997; 27:484-490.
17. Cutler RG. Urate and ascorbate: their possible roles as antioxidants in determining longevity of mammalian species. Arch Gerontol Geriatrics 1984; 3:321-348.

18. Chen PH, Yang XL. Research of free amino acid in pig hydatid cyst fluid. Chinese J Parasitol Parasitic Dis 1990; 8:181-184.

19. Chen PH, Wang FY, Zhang ZM. Albendazole effect on amino acid from pig hydatid cyst fluid in vitro. J Parasites Med Insect 1994; 1:27-31.

20. Jeffs SA, Arme C. Echinococcus granulosus (Cestoda): uptake of L-amino acids by secondary hydatid cysts. Parasitol 1988; 96:145-156.

21. Huang Y, Xu XZ. Comparation of cyst fluid biochemical characteristic from sheep and cattle in Xinjiang. Chinese J Zoo 1994; 10:27-31. 